\title{
Management of Higher Education Institutions in Uncertain Times: The Perspectives of University College
}

\author{
Mukole Kongolo \\ The Archbishop James University College (AJUCO) \\ Private Bag X466, Songea, Tanzania \\ Tel: 255-714-130-718. E-mail: kongolo@ajuco.ac.tz
}

Received: February 25, 2018 Accepted: March 24, 2019 Published: March 26, 2019

doi: $10.5296 /$ jsss.v6i2.14556

URL: https://doi.org/10.5296/jsss.v6i2.14556

\begin{abstract}
The purpose of this paper is to determine the state of management in university college, based on a review of academic literature. The aim is to provide university college with the best management evidence that inform their focus and models for quality improvement. Despite the growing role and importance of university colleges, they still strive to compete in increasingly uncertainty, difficult and challenging conditions. This paper is framed as a research informed analysis of key capabilities that managers will need to draw on in times of uncertainty. It is based on higher education literature as well as the researchers own observations. A framework of university college domain of practice is proposed to assist managers to deal with foreseeable future. The said domains or capabilities include: Setting Direction; develop the institution; develop staff; focus on teaching, learning and research; self management; influence others, and taking it into a broader context.
\end{abstract}

Keywords: Management capabilities, Abilities, Uncertain times, Environmental change, University college

\section{Introduction}

Uncertainty is the lack of certainty, a state of limited knowledge where it is impossible to exactly describe the existing situation or future outcome (Wikipedia, 2018). Uncertainty at work and the business world has made us all to think differently the way we make decisions and risks we take. When one is faced with an unknown situation, it forces him to think more critically on how to manage the situation, deal with adversity and prepare himself for the unexpected (Loch et al., 2006). In times of great change, complexity, and uncertainty, 
university managers face the challenges to adapt and navigate their ways through the tide of internal and external forces to create the best positive outcome for their institutions. Uncertainty seems to be constant than the way you can deal with it, defines your trajectory towards happiness and success (Lliopis, 2012). Uncertain times reveal reality and describe a test of resilience, of will and character, and as a result they are called "Survival of the Fittest". Since change is constant, it is your responsibility to create and sustain your own momentum. Opportunities are earned and you should trust yourself enough to earn them (Lliopis, 2012).

A university college like any other organisation has challenges. Chief among them are human resources needed to develop, deliver, assess, administer, and improve the educational processes. Equally important, an uncertain time poses a great challenging test to management responsible for running a university college. Recently, university colleges have been challenged to look for ways to do more to improve their status, while trying to increase both enrollment and access to higher education. In times of change and uncertainty, managers need to review the way they manage. Despite the need for managers to re-invent themselves in times of change as advocated in the literature (Drysdale \& Gurr, 2017), there a possibility that some practices will remain unchanged, even if the know-how that underpin these practices can change. In a University College set up, human resources are the strategic advantage of the institution. They are what differentiate a university college from one another. They provide a competitive advantage in terms of whether they have good management, outstanding faculty and excellent staff (Conley \& Yakoboski, 2008). In uncertain times some university college managers may be worried about the future of their institutions. According to research about $67 \%$ of managers will feel more pessimistic than they were in previous years (Jarvis, 2018).

Despite the unpredictability ahead, managers should continue to be confident in the resilience and adaptability of the university colleges, provided they get the right support. Changes to government policy and other arrangements have become the biggest concerns for university college managers (Jarvis, 2018). No matter the challenges, managers should project optimism about the future by being credible, honest, and accessible in communicating the challenges they face including their vision for moving forward. They need to be good listeners by moving out of their comfort zones and opening themselves up to hearing things that may be uncomfortable and challenging (Eisenman, 2010). There is a growing belief that managers need to find a style which is authentic for them, by adjusting their style in the context of the culture of the institutions where they work, the nature of the tasks to be completed and the characteristics and expectations of their team members (CMI, 2015). The Human Resource Office has a critical strategic role to play in identifying new competencies required to work in this highly dynamic environment and in creating new models for recruiting, training and motivating employees.

\subsection{The Problem}

University colleges have been facing increasing complexity in recent years, due to trends such as compliance with state organs requirements, outsourcing, and others. Under these conditions, it has become impossible to simply train students to reason in the same way as in the past. To continue in this static way will lead to a disaster. By adding to already complicated education environment, the historic levels of uncertainty increases even higher (Eisenman, 2010). In 
uncertain times even self-possessed students at the University College feel shaken, while others expect a bleak future. In interviews with more than 35 students at the Archbishop James University college (AJUCO), a powerful sense emerged that instead of feeling privileged, many of these students feel boxed in by anxieties and limitations (Depalmadec, 1991). If managers are to be effective in their role, they should think consciously about the way they manage, that is, what kind of management styles they should use best and will work well in their institutions. Using and adopting an appropriate management style can help managers establish trust, respect, rapport, engage their fellow, using and working towards building good working relationships (CMI, 2017). Adopting an inappropriate style can lead to employees becoming despondent and demotivated. In the same way, managers who adopt a style which is at "odds with the ethos of their institutions" will unlikely be successful (Christiensen \& Overdorf, 2000). Management style is primarily about how managers exercise their authority to get work done and successfully meet objectives. Another perception is that there is one best way to manage and achieve the best results in every situation (Mcdermott, 2017).

The purpose of this study is to emphasis on the ability to manage even in times of uncertainties, by adopting relevant styles that can assist you exercise your authority in the workplace and ensure that the objectives are achieved. It includes the ways in which managers plan, organise and carry their duties. In particular, it is about how you relate to, and deal with your colleagues. The key elements of management style include attitudes and behaviours, as well as what you say as a manager and how you say it; the example you set; your body language; and your general conduct (CMI, 2017). Furthermore, the paper attempts to answer to the following study question: "How can a manager ensures that his team effectively embrace uncertainty as a basis for growth and competitiveness?

\subsection{Objective}

The overall objective of this paper is to provide university college managers and leaders with management approaches and techniques in dealing with uncertain times, and to suggest a conceptual framework of the manager's tasks at these institutions.

\section{Review of Related Studies}

To provide a wider theoretical context, summaries of previous studies informing this paper are provided, with emphasis on management operations in a university college, including a look at previous studies on management in higher education. Experience suggests that we have been living in a period of uncertainty and transformational change for a long time. Johansen et al. (2012) called this period a period of volatility, complexity, uncertainty and ambiguity. Innovations that have been taking place in these varied contexts were responses to such transformational change. Oxford Dictionary (2018) describes this phenomenon as the state of confusion resulting from critical changes in work environment landscape, which lead to unsettling conditions in many organisations. Some others have called it a form of increasing political concerns about the overall state of affairs in university colleges (Depalmadec, 1991; Hibbert \& Cunliffe, 2015). These concerns have led some government organs and institutions to question the relevance of skill sets developed in university colleges, including the relevance of these skill sets to job opportunities for graduates (Graig, 2017). Following Shah (2012), the focus should be on reconsidering and renewing strategic planning in universities especially at a 
time of uncertainty.

Wren et al. (2002), suggested the use of following 14 principles of management in managing institutions, because they are useful tools for forecasting, planning, process management, organization management, decision-making, coordination and control. Although they are obvious, many of these matters are still used on the basis of common sense in current management practices in organizations (Table 1).

Table 1 . The 14 principles of management

\begin{tabular}{ll}
\hline 1. Division of Work & 8. The Degree of Centralization \\
\hline 2. Authority and Responsibility & 9. Scalar Chain \\
3. Discipline & 10. Order \\
4. Unity of Command & 11. Equity \\
5. Unity of Direction & 12. Stability of Tenure of Personnel \\
6. Subordination of Individual Interest & 13. Initiative \\
7. Remuneration & 14. Esprit de Corps \\
\hline
\end{tabular}

Source: Wren et al., (2002).

Van Vliet (2011), used the five functions of management of Henri Fayol to explain management in a practical way. They argued that at the beginning of the last century, Fayol created the first principles of the classical management theory. Management steps were created leading to solving problems in a creative manner. Finding a creative solution is often more difficult than discovering what the problem is, than making choices or decision-making process (Figure 1). Uncertain times are generally considered in the broader socioeconomic context of higher education, that is, what uncertain time means for management of a university college. If we refer to the socioeconomic context, it can be argued that the nature of our environment is no longer stable. An example of this instability is a change in climate conditions, the most biggest threat the world has been facing (WWF, 2018). Overall, it can be expressed that both political, economic, social, and environmental conditions have significant impacts on the people including managers of institutions (Elkington, 1997). Based on these and many other factors, some questions have been raised about the manner in which managers define work, the way it should be done, and the relationships that underpin the work. Tamimi and Sebastianelli (2017) said that in the middle of what appears to be a moral crisis, institutions are under pressure to manage and justify behavior by evaluating environmental, social, and governance performance. 


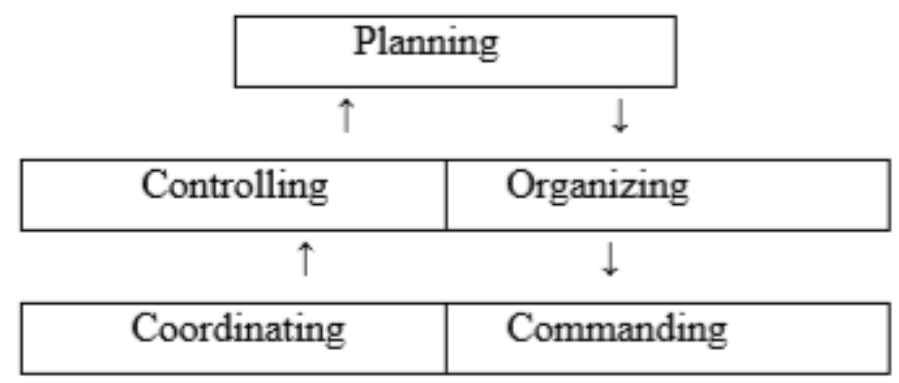

Figure 1. Five functions of management

In line with the literature, management theories can be used to understand and characterise the nature of uncertain times (Karim et al., 2016), as well as environmental uncertainty and responses to all above (Bogers et al., 2015). The development of new curricula, content, and other educational requirements for the changing times need to be given some considerations in many university colleges. Sustainability issues including formation and retention of competent human resources are the responsibility of management (Pesonen, 2003).

Complex situations require managers to develop increased ways of understanding such situations (Bartunek et al., 1983). For management in a university college the impact of uncertain times can resonate long after it has passed. That is, in the years ahead, they may see a kind of golden age of academic prosperity that was brought to a crashing end by uncertain times. The end of the golden age can create a golden opportunity for a university college to implement the management philosophies, including strategies and actions that will shape its future strongly (Higdon, 2007). Communicating what we do is important and why we are doing it is even more important. With all that we do, we must be sure to keep the lines of communication open among our peers, institutions and industry associations as well (Alessandri et al., 2004). We all need to reach out to colleagues, share our concerns, and discuss options. Discuss new approaches, new ideas, new concepts and how they might be applied to your own university college (Higdon, 2007).

\section{Methodology}

This paper is based on the literature review of overall management system in higher education institutions. It is a descriptive research that describes and analyses characteristics of management phenomenon being investigated in university colleges (Friedland, 2008; Beech et al., 2010; Hibbert \& Cunliffe, 2015; Tari \& Dick, 2016; Drysdale \& Gurr, 2017). Once the existing body of literature was completed, a conceptual framework for this paper was provided following Drysdale and Gurr (2017) as shown in Figure 2. 


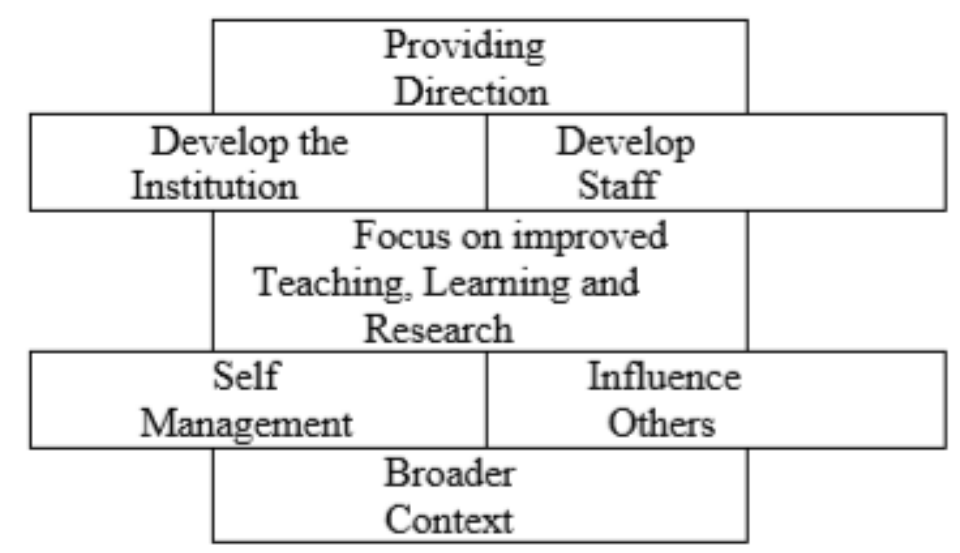

Figure 2. A framework depicting the domains of management in a university college

The most important domains of management in a university college set up are shown in figure 2. The conceptual framework was developed based on the literature of management in higher education (Drysdale \& Gurr, 2017). The design was mainly to ensure the widest coverage in literature review. The seven fundamental domains framework were used to explore the knowledge base about university college management (Drysdale \& Gurr, 2017). The said domains included an understanding the context, that is: providing direction; develop the institution; develop staff; focus on improved teaching, learning, and research; self management; influence others; and the broader context. These domains are key components that are most likely to sustain a university college to succeed in uncertain times. As key components, they need to be reviewed and possibly re-shaped with time. The framework itself provides important explanations of the main ideas on management that have been explored and developed in literature (Drysdale \& Gurr, 2017).

\section{Discussion}

There is a need to identify the types of talent that can play well in uncertain times. The Human Resource Division is responsible for identifying new competencies needed for future success and recommend them for placements. It is important to build employee confidence in the manager's vision for the future of the institution, and how to get there in times to come. The focus by most employees tend to be mostly on the "here" and "now" through many concern about their job security (Shah, 2012). A framework depicting the domains of management in a university college (Figure 1) suggests that managers are compelled to providing direction to the institution, so that its objectives are achieved. You should provide the institution with any forms of academic development such as its viability in terms of quality teaching and a conducive learning environment. Promote staff development to increase the number of highly qualified staff in the institution. Focus on improving teaching and learning and create a culture of research in the institution, as the core business of the institution. Manage the way you interact, deal and speak to your colleagues and other people. Let your behavior speak itself to other people instead of you as a person, and then take it to the other side in broader sense. As a manager, you need to be optimistic and aggressive in the pursuit of the future, at the same time stabilizing the present, this is very important during uncertain times (Drysdale \& 
Gurr, 2017). In so doing, managers need to be credible, honest, and accessible to employees, because they expect more from their managers by watching and listening more closely during uncertain times, and yourself manager you must be a good listener. During this time, more transparency and communication are much needed. Some managers have always been exposed to hearing good news, however, during uncertain times it is critical to be open to hearing news that may sometimes be uncomfortable and challenging.

As a manager, you need not to be surrounded with people who create all sort of barrier, as this increases the probability of failure as a result of isolation (Friedland, 2008). Be a manager who is open to hearing and seeing the full range of opportunities, including risks inherent in new initiatives, as to minimise the chances of failure and maximize the chances for success during difficult times (Friedland, 2008). No matter what it takes, the uncertain times mean that as a manager you must get out of your comfort zone and perform according to the expectations of your institution. No institution can be open to opportunity if its management is closed to discomforting news and feedback (Drysdale \& Gurr, 2017). As a manager, trusts your teammates, seeks and acts on their ideas and involves them in setting goals and to finding solutions. Some of the drivers of managerial behavior include concerns for getting the job done and for the people involved. Research suggests that managers should communicate, persuade, show, consult, ask, share and involve. They need to be ready to adjust their style to suit the context, and be attentive to the needs of both individual and group (Williams, 2009; CMI, 2015). From the literature we learn that during times of uncertainty, successful executives lead their institutions in a yellow-light mode, by being strong leaders who exercise cautious including thoughtful assessment before taking actions and risks. Simply because uncertainty elicits instability and insecurity in organizations' cultures and staff (Friedland, 2008).

University college can come out of this difficult period stronger, but it will require focus and fundamental change. It will need to look forward and forget past uncertain times. Interrogate yourself if your approach needs change?, if so, how will the institution adapts while continuing to uphold its mission and pursue its vision? This is a good time to be innovative, to try new approaches whether in the classroom or beyond (Mcdermott, 2017). Then focus on the educational mission, achieve the essential student outcomes to which you aspire and foster an environment that supports students' exploration and self-discovery to the maximum degree. This kind of education requires significant ongoing investment in people, programs, and infrastructure, and the returns on this investment will last for a lifetime (Johansen et al., 2012). Management style refers to the way a manager makes decisions relating to their subordinates and institution. Choosing a wrong management style results in clashes within the institution and creates a recipe for disaster. More often wrong styles de-motivates employees, affects productivity and lead employees to disengage by leaving the institution. Choosing the right management style is the best option, it helps you to show those around you that you are indispensable and beneficial for them and for the institution (Mcdermott, 2017).

The disruptive effects or chaotic situations frequently affect institution's workforce by lowering morale, increasing absenteeism and sick leave, heightened stress and uncertainty, loss of key staff, and lowered productivity. Management team at university colleges typically experiences increased scrutiny, pressures for immediate responses, difficulties in retaining 
key staff, and loss of confidence (Johansen et al., 2012). Managers need to adopt productive ways to deal with these critical unsettling situations. They should manage the emotional distress, and at the same time being a source of strength and stability for others (Johansen et al., 2012). This involves enduring behaviors and actions developed during the coping with disruptive changes (Friedland, 2008). As imperfect situation is advancing relentlessly towards uncertain future scenarios, we must try to redirect it toward sustainability. This means we need to look towards new ways of doing things in order to improve our situations to achieve social justice, equality and stability. Changing situations is impossible without learning, just as learning is impossible without changing situations (Jesús, 2011).

Change is part of life, sometimes it is positive while some other times it is less positive. But regardless of what form it comes in, you have a choice to either ride the wave of change, or let it crash upon you as you struggle to remain afloat (Robbin, 2018). It is easy to adopt a "laissez faire attitude" when uncertainty and turbulence come your way. This is the path of least resistance of stepping back and watch as the things unfold and take their own course. The secret to handling change is to focus on progress (Richtnér \& Löfsten, 2014). When you are lost, or trapped in an emotional fog, it is difficult to even make sense of what is happening, let alone understand what steps to take to move forward. You can bring a sense of certainty to an uncertainty and chaotic situation. It requires creation of a vision for what it is that you truly want and say "okay", I am not going to just sit here and hope everything will be fine, I am going to take control of this situation (Robbin, 2018).

\section{Conclusion}

Uncertainty is the lack of certainty, a state of limited knowledge where it is impossible to exactly describe the existing state of affairs and a future outcome. Uncertainty at work and the business world has made us all think differently the way we make decisions and risks we take. When one is faced with an unknown situation, it forces him to think more critically on how to manage the situation, deal with adversity and prepare himself for the unexpected. In times of great change, complexity, and uncertainty, university college managers face the challenge to adapt and navigate their ways through the tide of internal and external forces, to create the best positive outcome for institutions. Uncertainty may be constant than the way we may deal with it and may defines the trajectory towards happiness and success. Uncertain time reveal reality and describes a test of resilience, will as well as character, and it represents what is called "Survival of the Fittest". Since change is constant, it is the manager's responsibility to create and sustain own momentum. Opportunities are earned and you should trust yourself enough to earn them.

The challenges faced by university colleges are numerous. Chief among them are human resources needed, deliver, assess, administer, improve the educational processes and deal with uncertain times. Equally important, an uncertain time poses a great challenging test to management responsible for running a university college. In times of change and uncertainty, managers need to review the way they manage through the styles they use. Human resources are the strategic advantage of a university college. It is what differentiates a university college from one another. It provides a competitive advantage in terms of whether a university college has a good management, outstanding faculty and excellent staff.

Some managers in university colleges may be worried about their future in uncertain times. 
However, despite the unpredictability ahead, managers should continue to be confident in the resilience and adaptability of the institution, provided they get the right support. No matter the challenges, managers should project optimism about the future by being credible, honest, and accessible in communicating the challenges they face, including their vision for moving forward (Andersen et al., 2018). They need to be good listeners by moving out of their comfort zones and opening themselves up to hearing things that may be uncomfortable and challenging. They need to find authentic styles to adjust to, in the context of the culture of the institution they work, the nature of the tasks to be completed, and the characteristics and expectations of their team members. Communicating what we do is important and why we are doing it is even more important. With all that we do, we must be sure to keep the lines of communication open among our peers. We all need to reach out to colleagues, share our concerns, and discuss options. Discuss new approaches, new ideas, new concepts and how they might be applied to own university college is the best way to manage.

\section{Acknowledgement}

The author would like to thank the Administration and Finance Department at AJUCO for the payment of this paper's publication.

\section{Conflict of Interests}

The author declares to have no conflict of interests as far as this paper is concerned..

\section{References}

Alessandri, T. M., Ford, D. N., Lander, D. M., Leggio, K. B., \& Taylor, M. (2004). Managing risk and uncertainty in complex capital projects. The Quarterly Review of Economics and Finance, 44(5), 751-767. https://doi.org/10.1016/j.qref.2004.05.010

Anderson, L., Hibbert, P., \& Mason, K. (2018). Management Education in Turbulent Times. Journal of Management Education, 42(4), 423-440. https://doi.org/10.1177/1052562918 779421

Beech, N., MacIntosh, R., \& MacLean, D. (2010). Dialogues between academics and practitioners: The role of generative dialogic encounters. Organization Studies, 31, 1341-1367. https://doi.org/10.1177/0170840610374396

Bogers, M., Boyd, B., \& Hollensen, S. (2015). Managing turbulence: Business model development in a family-owned airline. California Management Review, 58(1), 41-64. https://doi.org/10.1525/cmr.2015.58.1.41

Bridgman, T., Cummings, S., \& McLaughlin, C. (2016). Restating the case: How revisiting the development of the case method can help us think differently about the future of the business school. Academy of Management Learning \& Education, 15, 724-741. https://doi.org/10.5465/ amle.2015.0291

CMI. (2017). Understanding Management And Leadership Styles Checklist 256. Chartered Management Institute (CMI). Retrieved from https://www.managers.org.uk/ /media/

Christiensen, C., \& Overdorf, M. (2000). Managing the Challenge of Disruptive Change. Harvard Business Review, 78, 66-76.

Craig, R. (2017). The top 10 higher education issues we all agree on. Retrieved from https://www.forbes.com/sites/ryancraig/2017/01/20/the-top-10-higher-education-issues-we-al 
1-agree-on/\#1af9f601fa87

Conley, V. M., \& Yakoboski, P. J. (2008). Managing higher education in uncertain economic times (pp. 1-16). Advancing Higher Education, TIAA-Cref Institute

Depalmadec, A. (1991). In Uncertain Times, College Students See a Bleak Future After Graduation. The New York Times Company.

Eisenman, E. (2010). Leading your Talents in Uncertain Times. Retrieved from http://www.babson.edu/academics/executive-education/babson-insight/leadership-and-manag ement/leading-your-talent-in-uncertain-times

Elkington, J. (1997). Cannibals with forks: The triple bottom line of 21st century business. Gabriola Island, British Columbia, Canada: New Society

Friedland, L. (2008). Leading the Organization During Uncertain Times. Retrieved from https://www.apadivisions.org/division-31/publications/articles/california/friedland.pdf

Hibbert, P., \& Cunliffe, A. (2015). Responsible management: Engaging moral reflexive practice through threshold concepts. Journal of Business Ethics, 127, 177-188. https://doi.org/10.1007/s10551-013-1993-7

Higdon, L. I. Jr. (2007). Building a Strong Future for Higher Education: Strategies for Tough Economic Times. Association of American Universities, A Voice and Force for Liberal Education in the $21^{\text {st }}$ Century. Retrieved from https://www.aacu.org/publications-research/ periodicals/building-strong-future-higher-education-strategies-tough-economic

Jarvis, A. (2018). There is only so much uncertainty universities can take. The Guardian.

Jesús, G. (2011). The Challenges of Higher Education in the 21st Century. Global University Network for Innovation. Retrieved from http://www.guninetwork.org/articles/challengeshigher-education-21st-century

Johansen, B. (2012). Leaders Make the Future. San Francisco, CA: Berrett-Koehler Publishers, Inc.

Johansen, A., Ekambaram, A., Krane, H. P., \& Steiro, T., (2012). Uncertainty Management Myths and Realities, Paper presented at the EURAM conference, Rotterdam, The Netherlands.

Karim, S., Carroll, T. N., \& Long, C. P. (2016). Delaying change: Examining how industry and managerial turbulence impact structural realignment. Academy of Management Journal, 59, 791- 817. https://doi.org/10.5465/amj.2012.0409

Lliopis, G. (2012). 5 Things we learn about our selves during uncertain times. Forbes Daily Dozen. Retrieved from https://www.forbes.com/sites/glennllopis/2012/11/26/5-things-welearn-about-ourselves-during-uncertain-times/\#3e0c3fca6280

Loch, C. H., De Meyer, A., \& Pich, M. T. (2006). Managing the unknown: A new approach to managing high uncertainty and risk in projects. Hoboken, NJ: Wiley. https://doi.org/10.1002/ 9780470172377

Mcdermott, E. (2017). The top 7 management styles: Which ones are most effective? Retrieved from https://www.workzone.com/blog/management-styles/

Oxford English Dictionary. (2018). Oxford, England: Oxford University Press.

Pesonen, H.-L. (2003). Challenges of integrating environmental sustainability issues into 


\section{Macrothink}

Journal of Social Science Studies

ISSN 2329-9150

2019, Vol. 6, No. 2

business school curriculum: A case study from the University of Jyväskylä, Finland. Journal of Management Education, 27, 158-171. https://doi.org/10.1177/1052562903251412

Richtnér, A., \& Löfsten, H. (2014). Managing in turbulence: How the capacity for resilience influences creativity. $R \& D$ Management, 44, 137-151. https://doi.org/10.1111/radm.12050

Robbin, T. (2018). Certainty in uncertain times. 6 Mandates for designing the life you want. Robbin Research International Inc.

Shah, M. (2012). Renewing strategic planning in universities at a time of uncertainty. Perspectives: Policy and Practice in Higher Education, 1.

Tamimi, N., \& Sebastianelli, R. (2017). Transparency among S\&P 500 companies: An analysis of ESG disclosure scores. Management Decision, 55, 1660-1680. https://doi.org/10.1108/MD01-2017-0018

Tari, J. J., \& Dick, G. (2016). Trends in quality management research in higher education institutions. Journal of Service Theory and Practice, 26(3), 273-296. https://doi.org/10. 1108/JSTP-10-2014-0230

Van Vliet, V. (2011). Five Functions of Management (Fayol). Retrieved from https://www.toolshero.com/management/five-functions-of-management/

Williams, M. (2009). How to build and keep workers' trust in a crisis. Society for Human Resource Management (SHRM). Retrieved from https://www.shrm.org/resourcesandtools/hrtopics/behavioral-competencies/leadership-and-navigation/pages/buildtrustincrisis.aspx

Wren, D. A., Bedeian, A. G., \& Breeze, J. D. (2002). The foundations of Henri Fayol's administrative theory. Management Decision, 40(9), 906-918. https://doi.org/10.1108/ 00251740210441108

\section{Copyright Disclaimer}

Copyright for this article is retained by the author(s), with first publication rights granted to the journal.

This is an open-access article distributed under the terms and conditions of the Creative Commons Attribution license (http://creativecommons.org/licenses/by/3.0/). 